\title{
The moderating role of perceived social support on early maladaptive schemas and well-being for primary caregivers of dementia patients
}

\author{
Elcin Yorulmaz ${ }^{(1)}$, Ozlem Bozo ${ }^{2(D)}$ \\ 'Dokuz Eylül University, Department of Psychology, Izmir, Turkey \\ ${ }^{2}$ Middle East Technical University, Ankara, Turkey
}

\begin{abstract}
Objective: This study aims to investigate the moderating role of perceived social support on early maladaptive schemas and well-being for primary caregivers of dementia patients.

Method: Ninety-nine adult children as the primary caregivers of dementia patients participated in the study. They completed the measures of Young Schema Questionnaires-Short Form 3 (YSQ-SF3), Caregiver Well-Being Scale, and Multidimensional Scale of Perceived Social Support (MSPSS).

Results: According to the results of the regression analyses, total perceived social support and perceived social support from significant others moderated the association of early maladaptive schemas and caregiver well-being-basic needs, unlike the perceived social support from family and perceived social support from friends. For the early maladaptive schemas and caregiver well-being-activities of living association, however, the moderator roles of total perceived social support and perceived social support from different sources were not confirmed.

Conclusion: Since caregiving has negative effects on caregivers, it is important to identify the protective factors. The findings emphasize the buffering role of perceived social support from significant others, especially in terms of meeting basic needs, in the caregiving process.
\end{abstract}

Keywords: Caregiving, caregiver well-being, dementia, early maladaptive schemas, perceived social support

\section{INTRODUCTION}

In Turkey, the rate of the population over the age of 65 increased rapidly and reached up to $9.1 \%$ in 2019 (1). As a result of the changing demographic profile, the number of dementia patients also increases (2). It is stated that there are 47.47 million individuals diagnosed with dementia in the world in 2015 (3). Studies on the prevalence of dementia in Turkey showed that the rate of dementia patients varies from $8.4 \%$ to $20.0 \%$ (4-6). Dementia is the general name of conditions characterized by the deterioration of memory, language, problem solving, and other thinking skills that affect the individual's daily life (7). The majority of individuals diagnosed with dementia $(70 \%)$ are those with Alzheimer's Disease, followed by vascular dementia $(17 \%)$ and other related conditions (13\%; e.g., Parkinson's disease and Lewy body dementia) (8).

How to cite this article: Yorulmaz E, Bozo O. The moderating role of perceived social support on early maladaptive schemas and well-being for primary caregivers of dementia patients. Dusunen Adam The Journal of Psychiatry and Neurological Sciences 2021;34:346-358.

Correspondence: Elcin Yorulmaz, Dokuz Eylul University, Department of Psychology, Izmir, Turkey 
Thus, the prevalence of dementia shows a gradually increasing trend and leads to loss of skills that greatly affect the daily lives of individuals.

Caregiving means meeting the health needs of another and includes helping with activities of daily living as well as providing emotional support (9). The primary caregiver is defined as the person with the highest responsibility in terms of providing care (9). The caregivers of dementia patients are spouses $(61 \%)$ (10), children (29\%), or other relatives and friends (11). In this sense, not only patients but also their families and friends are affected by dementia on personal, emotional, financial, and social levels (12). Ballard (1989) described dementia as a "funeral that never ends" because caregivers face many losses over the course of the illness instead of one final loss (as cited in 13, no paging). This supported the claim that dementia caregivers are affected from this process more negatively than caregivers of patients (14).

Psychological well-being is "a subjective state that results from many long-standing factors as well as situation specific stressors related to caregiving, and it is an important outcome measure" (15). It was stated that the well-being of the caregiver is affected by the level of meeting the needs in two areas, namely basic and non-basic needs (16). Therefore, in the present study, caregiver well-being was operationally defined as the extent to which the caregivers meet their basic needs and perform the activities of living. Studies showed that half of the dementia caregivers spend at least 46 hours per week responding to the patients' needs (17); as the disease worsens, the duration increases (18). Therefore, caregivers do not have enough time to perform positive health behaviors such as following an appropriate nutritional regimen, going to doctor visits, doing routine exercises, or getting sufficient sleep (19-21), and half of them completely end or reduce the time of their occupation (17). Considering the tasks carried out by caregivers and the time spent on these activities, it is not surprising that caregivers experience burden (22) and stress (23-28). Due to chronic exposure to stress, caregivers of dementia patients have adverse health outcomes (29) such as coronary heart disease (30), hypertension (31), and impaired immune function (32). In terms of psychological outcomes, caregivers of dementia patients reported anxiety (33), and depression (34). In sum, caregiving practices dramatically affect both the psychological and physical well-being of the caregivers.

As the literature suggests, caregiving affects both the psychological and physical well-being of the caregivers. One of the psychological variables in this process may be early childhood experiences. As Bowlby stated in his attachment theory in 1988, these experiences with significant others determine organized thoughts and feelings about the self, others, and the world, and the individual's perception and response to new experiences (35-37). These organized thoughts, behaviors, and feelings are schemas, which provide individuals with cognitive maps of how to manage social relationships, some of which may be maladaptive in nature. Early maladaptive schemas (EMSs) are defined as "a broad pervasive theme or pattern; comprised of memories, emotions, cognitions, and bodily sensations; regarding one's self and one's relationship with others; developed during childhood or adolescence; elaborated through one's life time; dysfunctional to some degree" (38). Everyone has at least one of the EMSs that starts in early development and recurs throughout life. In adulthood, life events trigger schemas in which these events are perceived unconsciously, similar to traumatic experiences in their childhood. Although not all schemas are traumatic in origin, all EMSs are destructive and most schemas are caused by regularly repeated noxious experiences throughout childhood and adolescence. These experiences are cumulative in nature. They give rise to a fully developed schema that is regarded as a priori truths, thus affecting the processing of later experiences as well (38). Schemas develop as a result of basic emotional needs that are not met in childhood, which are secure attachment to others, including safety, stability, nurturance, and acceptance; autonomy, competence, and a sense of identity; freedom to express valid needs and emotions; spontaneity and play; and lastly, realistic limits and self-control. These needs are believed to be universal and some individuals have stronger needs than others (38).

EMSs have also impact on the individuals' well-being. In general, they are important in the development and maintenance of psychiatric symptoms (39), such as mood disorders (40), anxiety disorders (41), eating disorders (42), sexual dysfunction disorder (43), schizophrenia (44), chronic pain disorder (45), alcohol addiction (46), opiate addiction (47), substance abuse disorder $(42,48)$, and personality disorder symptoms (49). Based on the above-mentioned literature, systematic findings indicate the association between EMS and well-being. However, to the best of our knowledge, there is no research investigating the association between EMS and caregiver well-being. Rather, there are mostly attachment theory-based 
studies of caregiver well-being and early life experiences. Attachment was also found to be related to EMSs (50, 51). In fact, there are studies indicating the mediator role of EMSs in the association between attachment and psychopathology (52), such as depression (53). The importance of attachment for caregivers was shown in many studies $(13,54)$. It was found that caregiver attachment was associated with the probability of providing support and care (55) and quality of the caregiving (56). In terms of attachment and caregiver well-being, the attachment was found to be related with caregiver well-being $(13,57)$. This finding was also confirmed in studies conducted with children of dementia patients $(56,58)$.

This pattern between EMS and well-being can be mitigated with social support. Social support is defined as "information leading the subject to believe that he (or she) is cared for and loved, esteemed, and a member of a network of mutual obligations" (59). According to the stress-buffer hypothesis, psychosocial stress negatively affects the physical and/ or psychological well-being of a person with little or no social support. However, strong social support reduces or eliminates this effect (60). According to Lahey and Cohen (2000), there are two types of social support: received vs. perceived social support. Received social support is defined as the actual amount and frequency of social support received by others, while perceived social support is based on individuals' perceptions about the available social support they receive the social environment (61). As there is a stronger association with psychological health (62) and burden (63) than with the received social support, most of the researchers used perceived social support as their subject of investigation (64). Thus, perceived social support was used in this study as a moderator variable.

There are many studies investigating the association between perceived social support and both the psychological and physical well-being of patients and caregivers $(65,66)$. For instance, the psychological well-being of caregivers dementia patients was found to be strongly correlated with their perceived social support (67). However, caring for a patient with dementia takes an enormous amount of time, which reduces the time available for caregivers' social interactions. With less time for social interactions, the gradual loss of a loved one worsens the perceptions of social support (68). Hence, caregiving worsens even the way that social support is perceived (69). In the light of the literature mentioned above, the aim of the present study is to investigate the association between EMS and caregiver well-being in primary caregivers of dementia patients and the moderator role of perceived social support on this association.

\section{METHOD}

\section{Sample}

Ninety-nine adult children as the primary caregivers of dementia patients (mean age $=51.20, \mathrm{SD}=7.57$ ) participated in this study. The inclusion criterion, being the primary caregiver of a dementia patient, can be defined as the person responsible for assisting the patient in his/her daily needs and providing supervision to the person in need. The inclusion criteria for the study was the absence of any physical or psychological disorder that would prevent reliable data collection. Twenty-four (24.2\%) participants were giving care for mild dementia patients, 50 (50.5\%) moderate dementia patients, and 25 (25.3\%) severe dementia patients (Table 1).

\section{Measures}

Demographic Information Form: Demographic information form was developed by the researcher. It includes questions about the participants' age, sex, marital status, educational status, employment status, job, number of children, where they spend most of their life, economic status, presence of psychiatric and physical disorders and their treatment history, and finally their dementia level. The dementia levels of the patients were taken from the patients' medical reports. In other words, the data on the dementia level in this study are based on the objective criteria.

Young Schema Questionnaire-Short Form 3 (YSQSF3): YSQ-SF3 was developed to evaluate EMS with 90 items. It is a self-report questionnaire answered on a six-point scale ranging from describes me perfectly to completely untrue of me (70). Higher scores on the schemas indicate that schemas are more likely to be found (70). This questionnaire was adapted to Turkish and showed 14 different schemas on five schema domains. These schema domains include impaired autonomy (enmeshment/dependence, abandonment, failure, pessimism, and vulnerability to harm), disconnection (emotional deprivation, emotional inhibition, social isolation/mistrust, and defectiveness), unrelenting standards (unrelenting standards, and approval-seeking), impaired limits (entitlement/ insufficient self-control), and other-directedness (self-sacrifice, and punitiveness). The Turkish YSQ-SF3 
Table 1: Demographic characteristics of participants

\begin{tabular}{|c|c|c|c|c|c|c|c|c|c|c|}
\hline Variables & $\mathbf{N}$ & $\%$ & M & SD & $\mathbf{R}$ & Variables & $\mathbf{N}$ & $\%$ & M & SD \\
\hline Gender & & & & & & Village & 1 & 1 & & \\
\hline Female & 78 & 78.8 & & & & Economic status & & & & \\
\hline Male & 21 & 21.2 & & & & Low & 9 & 9.1 & & \\
\hline Age & & & 51.20 & 7.57 & $25-64$ & Middle & 86 & 86.9 & & \\
\hline Marital status & & & & & & High & 4 & 4 & & \\
\hline Single & 12 & 12.1 & & & & Presence of psychiatric disorder & & & & \\
\hline Married & 67 & 67.7 & & & & Yes & 17 & 17.2 & & \\
\hline Divorced & 14 & 14.1 & & & & No & 82 & 82.8 & & \\
\hline Widowed & 6 & 6.1 & & & & Name of psychiatric disorder & & & & \\
\hline Education level & & & & & & Depression & 10 & 10.1 & & \\
\hline Primary school & 21 & 21.2 & & & & Anxiety disorder & 6 & 6.1 & & \\
\hline High school & 29 & 29.3 & & & & Depression \& anxiety & & & & \\
\hline University & 39 & 39.4 & & & & disorder & 1 & 1 & & \\
\hline Master's/doctorate & 10 & 10.1 & & & & Presence of physical disorder & & & & \\
\hline Working status & & & & & & Yes & 29 & 29.3 & & \\
\hline Employed & 36 & 36.4 & & & & No & 70 & 70.7 & & \\
\hline Unemployed & 63 & 63.6 & & & & Psychological treatment & & & & \\
\hline Number of children & & & & & & Yes & 18 & 18.2 & & \\
\hline 0 & 17 & 17.2 & & & & No & 81 & 81.8 & & \\
\hline 1 & 24 & 24.2 & & & & Physical treatment & & & & \\
\hline 2 & 53 & 53.5 & & & & Yes & 26 & 26.3 & & \\
\hline 3 & 5 & 5.1 & & & & No & 73 & 73.7 & & \\
\hline Residence & & & & & & Level of the dementia & & & & \\
\hline Metropolis & 83 & 83.8 & & & & Mild & 24 & 24.2 & & \\
\hline City & 12 & 12.1 & & & & Moderate & 50 & 50.5 & & \\
\hline Town & 3 & 3 & & & & Severe & 25 & 25.3 & & \\
\hline
\end{tabular}

was found to be a reliable and valid measurement tool (71). The internal consistency reliability of the inventory for the present sample was 0.93 .

Caregiver Well-Being Scale: The caregiver well-being scale is a self-report scale and has two subscales: basic needs and activities of living (16). These subscales measure how well the caregivers meet their basic needs and activities of daily living from a strengths-based perspective. In addition to physical needs such as sleep and nutrition, the basic needs subscale measures the expression of emotions, relaxation, and personal development. However, the activities of living subscale measures activities done in everyday life and leisure activities such as enjoying a hobby (16). Demirtepe and Bozo (2009) adapted the scale to Turkish culture with satisfactory reliability and validity (72). For the present sample, the internal consistency reliability coefficients were found as 0.89 for the basic needs subscale and 0.85 for the activity of living subscale.

Multidimensional Scale of Perceived Social Support (MSPSS): The MSPSS was developed to measure perceived social support from three different sources, family, friends, and significant other. MSPSS is a 12 -item self-report questionnaire on a 7 -point Likerttype scale ( $1=$ very strongly disagree, $7=$ very strongly agree). Higher scores on this scale mean higher levels of perceived social support (73). The Turkish version of the scale was adapted into Turkish by Eker and Arkar in 1995 (74). After the adaptation, the form was revised. The Cronbach's alpha reliability of the Turkish revised version ranges between 0.80 and 0.95 , and it has construct validity (75). In the present study, internal reliability coefficients were found to be 0.87 for the family subscale, 0.92 for the friends subscale, 0.93 for the significant other, and 0.90 for the total scale. 
Table 2: Intercorrelations among study measures

\begin{tabular}{|c|c|c|c|c|c|c|c|c|c|}
\hline \multirow[b]{2}{*}{ Measure } & \multicolumn{7}{|c|}{ Correlations } & \multirow[b]{2}{*}{ Mean } & \multirow[b]{2}{*}{ SD } \\
\hline & 1 & 2 & 3 & 4 & 5 & 6 & 7 & & \\
\hline 1. EMS & 1 & & & & & & & 211.95 & 44.38 \\
\hline 2. BN & $-0.28^{* *}$ & 1 & & & & & & 81.94 & 13.49 \\
\hline 3. $A L$ & -0.18 & $0.67^{* *}$ & 1 & & & & & 77.17 & 13.24 \\
\hline 4.TPSS & $-0.25^{*}$ & $0.49^{* *}$ & $0.34^{* *}$ & 1 & & & & 65.08 & 16.03 \\
\hline 5. PSSFA & -0.18 & $0.42^{* *}$ & $0.26^{*}$ & $0.53^{* *}$ & 1 & & & 24.68 & 4.72 \\
\hline 6. PSSFR & $-0.25^{*}$ & $0.41^{* *}$ & $0.30^{* *}$ & $0.85^{* *}$ & $0.21^{*}$ & 1 & & 21.40 & 7.21 \\
\hline 7.PSSSO & -0.16 & $0.36^{* *}$ & $0.25^{*}$ & $0.90^{* *} 0$ & $0.28^{* *}$ & $0.67^{* *}$ & 1 & 19.00 & 8.24 \\
\hline
\end{tabular}

Note 1: Pearson correlation coefficient, ${ }^{*} \mathrm{p}<0.05,{ }^{* *} \mathrm{p}<0.01$; Note 2: EMS: Early maladaptive schemas; BN: Caregiver well-being scale-basic needs; AL: Caregiver well-being scale-activity of living; TPSS: Total perceived social support; PSSFA: Perceived social support from family; PSSFR: Perceived social support from friends; PSSSO: Perceived social support from significant other.

\section{Procedure}

The data were collected from the Neurology Departments of hospitals in Izmir and Ankara, and the Alzheimer Association. Ethical approvals were obtained from the ethical committees of Middle East Technical University, hospitals, from the head of Neurology Departments of hospitals, and the Alzheimer Association. Before starting the study, a power analysis was performed with GPower 3.1.9.7 software to determine the sample size. As a result of the power analysis, it was concluded that the number of participants should be 73. After explaining the purpose of the study to the participants, an informed consent form was obtained. Then, the questionnaire sets were administered to the participants verbally. It took the researcher approximately 40 minutes to administer each questionnaire.

\section{Statistical Analyses}

Statistical Package for Social Sciences (SPSS), version 20 for Windows, was used in the current study for statistical analyses. At first, descriptive statistics of the measures of the study and demographic variables were conducted. Next, zero-order correlations were conducted to investigate intercorrelations among all measures of the study. Then, the moderator role of perceived social support between EMS and caregiver well-being was investigated via regression analyses. Five hierarchical regression analyses were performed. In the first two, the moderating role of total perceived social support in the association of EMS with caregiver well-being basic needs and caregiver wellbeing for the activities of living was investigated. Based on the results of these regression analyses, the moderating roles of different sources of perceived social support (i.e., perceived social support from family, friends, and significant others) in other regression analyses were examined solely on the basis of the association between EMS and caregiver well-being for the basic needs.

\section{RESULTS}

To reveal the associations among the measurements of the study, Pearson correlation coefficients were calculated (Table 2).

Following the examination of zero-order correlations, five hierarchical multiple regression analyses were conducted. Before running the regression analyses, the predictors and outcome variables were linearly transformed by subtracting the respective sample mean from each predictor to center the variables. Then, as Aiken and West (1991) suggested, variables were multiplied for the interaction term (76).

In the first two regression analyses, the moderating role of total perceived social support was examined using caregiver well-being-for basic needs and caregiver well-being for activities of living as the outcome variables, respectively. In the first step of the analyses, EMS and perceived social support were entered, and in the second step, the interaction term was entered.

In terms of caregiver well-being for basic needs, EMS $(\beta=-0.18, \mathrm{t}(96)=-2.04, \mathrm{p}<0.05)$ and perceived social support $(\beta=0.41, \mathrm{t}(96)=4.52, \mathrm{p}<0.001)$ were significantly associated with the caregiver well-being for basic needs $(\mathrm{F}(2,96)=17.64, \mathrm{p}<0.001)$. In the second step, the interaction of perceived social support and EMS revealed a significant association with the caregiver well-being for basic needs $(\beta=0.18$, $\left.\mathrm{t}(95)=2.06, \mathrm{p}<0.05, \Delta \mathrm{R}^{2}=0.03\right)$, (Fchange $(1,95)=4.25$, $\mathrm{p}<0.05)$. That is, perceived social support moderated the association between EMS and caregiver well-being for basic needs (Table 3). 
Table 3: Regression model predicting caregiver well-being-basic needs with early maladaptive schemas and perceived social support

\begin{tabular}{|c|c|c|c|c|c|c|c|}
\hline \multirow[b]{2}{*}{ Variable } & \multicolumn{7}{|c|}{ Caregiver well-being-basic needs } \\
\hline & B & SEB & $\boldsymbol{\beta}$ & $\mathbf{t}$ & $\Delta \mathbf{R}^{2}$ & $\Delta \mathbf{F}$ & df \\
\hline Step1 & & & & & 0.27 & $17.64^{* *}$ & 2.96 \\
\hline EMS & -0.06 & 0.03 & $-0.18^{*}$ & $-2.04^{*}$ & & & 96 \\
\hline PSS & 0.35 & 0.08 & $0.41^{* *}$ & $4.52^{* *}$ & & & 96 \\
\hline Step2 & & & & & 0.03 & $4.25^{*}$ & 1.95 \\
\hline PSSXEMS & 0.00 & 0.00 & $0.18^{*}$ & $2.06^{*}$ & & & 95 \\
\hline
\end{tabular}

Note 1: Hierarchical multiple regression; ${ }^{*} \mathrm{p}<0.05 ;{ }^{* *} \mathrm{p}<0.001$. Note 2: PSS: Perceived social support; EMS: Early maladaptive schemas.

Table 4: Regression models predicting caregiver well-being-activities of living with early maladaptive schemas and perceived social support

Caregiver well-being-activities of living

\begin{tabular}{|c|c|c|c|c|c|c|c|}
\hline Variable & B & SEB & $\boldsymbol{\beta}$ & $\mathbf{t}$ & $\Delta \mathbf{R}^{2}$ & $\Delta \mathbf{F}$ & df \\
\hline Step1 & & & & & 0.12 & $6.76^{*}$ & 2.96 \\
\hline EMS & -0.03 & 0.03 & $-0.10^{\text {ns }}$ & $-1.02^{\mathrm{ns}}$ & & & 96 \\
\hline PSS & 0.25 & 0.08 & $0.31^{* *}$ & $3.01^{*}$ & & & 96 \\
\hline Step2 & & & & & 0.00 & $0.13^{\text {ns }}$ & 1.95 \\
\hline PSSXEMS & 0.00 & 0.00 & $0.04^{\mathrm{ns}}$ & $0.36^{\mathrm{ns}}$ & & & 95 \\
\hline
\end{tabular}

Note 1: Hierarchical multiple regression; ns: Non-significant; ${ }^{*} \mathrm{p}<0.01$. Note 2: PSS: Perceived social support; EMS: Early maladaptive schemas.

Figure 1 shows the interaction effect of perceived social support and EMS on the caregiver well-being for basic needs. Using the proposed procedures (77), a simple regression of the caregiver well-being for basic needs on the EMS was computed for high (16.03) and low (-16.03) levels of perceived social support (i.e., $M+S D)$. Next, the slope of each regression line was tested to see whether they were statistically significant (76). This analysis revealed that the positive regression of caregiver well-being-basic needs on the EMS did not occur when perceived social support is low $(\beta=-0.35$, $\mathrm{t}(95)=-2.78, \mathrm{p}<0.01)$, but not when perceived social support is high $(\beta=-0.02, \mathrm{t}(95)=-0.14, \mathrm{p}=0.89)$. Accordingly, when perceived social support is high, there was no significant difference between the high and low EMS groups in predicting caregiver well-being for basic needs. In other words, if caregivers of dementia patients perceived higher levels of social support, having high or low schema scores did not make a difference in terms of their well-being levels. However, when perceived social support was low, there was a difference between the high and low EMS groups in predicting caregiver well-being for basic needs. That is, caregivers of dementia patients with high schema scores had lower well-being (i.e., less fulfilling their basic needs less) as compared to caregivers with low schema scores if they perceived low social support. Thus, perceived

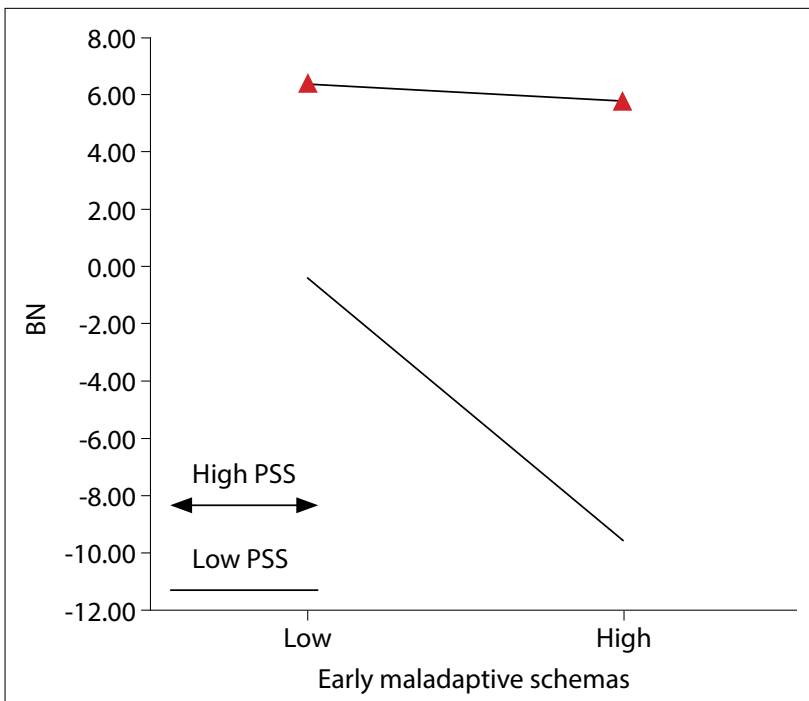

Figure 1. Interaction effect of perceived social support and early maladaptive schemas.

PSS: Perceived social support; BN: Caregiver well-being-basic needs.

social support can be a protective factor for caregivers of dementia patients with higher schema scores in terms of caregiver well-being for basic needs (Fig. 1).

The same procedure was repeated for the caregiver well-being for activities of living. While EMS was not significantly associated with caregiver well-being for 
Table 5: Regression analyses predicting caregiver well-being-basic needs with early maladaptive schemas and different sources of perceived social support

Regression analysis with perceived social support from family

\begin{tabular}{|c|c|c|c|c|c|c|c|}
\hline \multirow[b]{2}{*}{ Variable } & & \\
\hline & B & SEB & $\boldsymbol{\beta}$ & $\mathbf{T}$ & $\Delta \mathbf{R}^{2}$ & $\Delta \mathbf{F}$ & df \\
\hline Step1 & & & & & 0.22 & $13.20^{* * *}$ & 2.96 \\
\hline EMS & -0.06 & 0.03 & $-0.21^{*}$ & $-2.21^{*}$ & & & 96 \\
\hline PSSFA & 1.10 & 0.28 & $0.39 * * *$ & $3.93^{* * *}$ & & & 96 \\
\hline Step2 & & & & & 0.00 & $0.04^{\text {ns }}$ & 1.95 \\
\hline PSSFAXEMS & -0.00 & 0.00 & $-0.02^{\text {ns }}$ & $-0.19^{n s}$ & & & 95 \\
\hline
\end{tabular}

\begin{tabular}{|c|c|c|c|c|c|c|c|}
\hline \multirow[b]{2}{*}{ Variable } & \multicolumn{7}{|c|}{ Regression analysis with perceived social support from friends } \\
\hline & B & SEB & $\boldsymbol{\beta}$ & $\mathbf{T}$ & $\Delta \mathbf{R}^{2}$ & $\Delta \mathbf{F}$ & df \\
\hline Step1 & & & & & 0.20 & $11.96^{* * *}$ & 2.96 \\
\hline EMS & -0.06 & 0.03 & $-0.19^{*}$ & $-2.01^{*}$ & & & 96 \\
\hline PSSFR & 0.59 & 0.18 & $0.32^{* *}$ & $3.29 * *$ & & & 96 \\
\hline Step2 & & & & & 0.03 & $3.70^{\mathrm{ns}}$ & 1.95 \\
\hline PSSFRXEMS & 0.01 & 0.00 & $0.18^{\text {ns }}$ & $1.92^{\text {ns }}$ & & & 95 \\
\hline
\end{tabular}

\begin{tabular}{|c|c|c|c|c|c|c|c|}
\hline \multirow[b]{2}{*}{ Variable } & \multicolumn{7}{|c|}{ Regression analysis with perceived social support from significant others } \\
\hline & B & SEB & $\boldsymbol{\beta}$ & $\mathbf{T}$ & $\Delta \mathbf{R}^{2}$ & $\Delta \mathbf{F}$ & df \\
\hline Step1 & & & & & 0.18 & $10.63^{* * *}$ & 2.96 \\
\hline EMS & -0.07 & 0.03 & $-0.24^{* *}$ & $-2.70^{* *}$ & & & 96 \\
\hline PSSSO & 0.52 & 0.15 & $0.32^{* *}$ & $3.51^{* *}$ & & & 96 \\
\hline Step2 & & & & & 0.07 & $8.29^{* *}$ & 1.95 \\
\hline PSSSOXEMS & 0.01 & 0.000 & $0.26^{* *}$ & $2.88^{* *}$ & & & 95 \\
\hline
\end{tabular}

Note 1: Hierarchical multiple regression; ns: Non-significant; ${ }^{*} \mathrm{p}<0.05 ;{ }^{* *} \mathrm{p}<0.01 ;{ }^{* * *} \mathrm{p}<0.001$. Note 2 : PSSFA: Perceived social support from family; PSSFR: Perceived social support from friends; PSSSO: Perceived social support from significant others; EMS: Early maladaptive schemas.

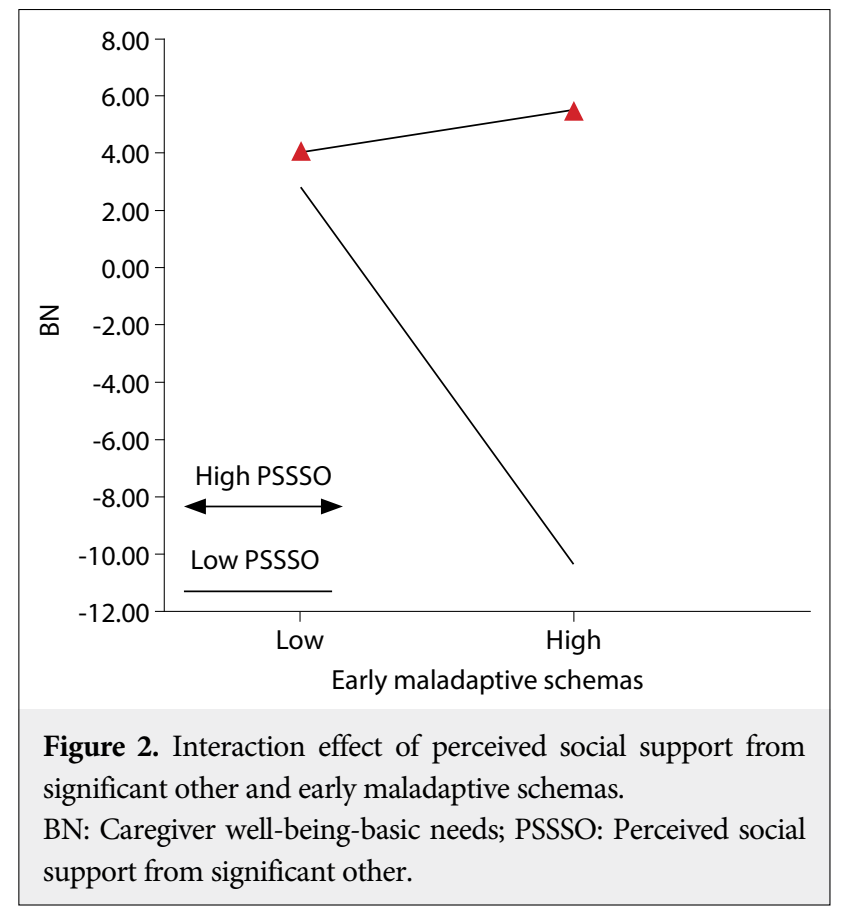

activities of living $(\beta=-0.10, t(96)=-1.02, p=0.31)$, perceived social support was significantly and positively associated with it $(\beta=0.31, \mathrm{t}(96)=3.01, \mathrm{p}<0.01$; $\mathrm{F}(2.96)=6.76, \mathrm{p}<0.01)$. The interaction of perceived social support and EMS revealed no significant association with caregiver well-being for activities of living $\left(\beta=0.04, \mathrm{t}(95)=0.36, \mathrm{p}=0.72, \Delta \mathrm{R}^{2}=0.00\right)$, (Fchange $(1.95)=0.13, \mathrm{p}=0.72)$. In other words, perceived social support did not moderate the association between EMS and caregiver well-being for activities of living (Table 4).

Since the moderator role of perceived social support in the association between EMS and the caregiver wellbeing for-basic needs was confirmed by the analyses, different sources of social support (i.e., family, friends, significant other) can be analyzed to determine which one of the sources really buffers for the negative effects of EMS. For all hierarchical regression models, EMS and one of the sources of perceived social support were entered into the equation in the first step. And in the second step, the interaction between EMS and respective perceived social support measure was entered into the equation.

According to regression analysis findings regarding the moderating role of perceived social support from the family in the association between EMS and caregiver 
well-being for basic needs, the EMS was significantly and negatively associated with the caregiver well-being for basic needs $(\beta=-0.21, t(96)=-2.21, p<0.05)$. The perceived social support from the family also revealed a significant relationship with the caregiver well-being for basic needs $(\beta=0.39, \mathrm{t}(96)=3.93, \mathrm{p}<0.001$; $\mathrm{F}(2.96)=13.20, \mathrm{p}<0.001)$. However, the interaction of perceived social support from family and EMS was not significant in predicting caregiver well-being for basic needs $\left(\beta=-0.02, \mathrm{t}(95)=-0.19, \mathrm{p}=0.85, \Delta \mathrm{R}^{2}=0.00\right.$; Fchange $(1.95)=0.04, p=0.85)$. Therefore, perceived social support from family did not moderate the relationship between EMS and caregiver well-being for basic needs. The same procedure was repeated for perceived social support from friends. EMS $(\beta=-0.19, \mathrm{t}(96)=-2.01$, $\mathrm{p}<0.05)$ and perceived social support from friends $(\beta=0.32, \mathrm{t}(96)=3.29, \mathrm{p}<0.01)$ were significantly associated with caregiver well-being for basic needs, $\mathrm{F}(2.96)=11.97, \mathrm{p}<0.001$. However, there was no significant moderation effect of perceived social support from friends $\left(\beta=0.18, t(95)=1.92, p=0.06, \Delta R^{2}=0.03\right)$, (Fchange $(1.95)=3.70, \mathrm{p}=0.06)$ on the relation between EMS and caregiver well-being for basic needs. Finally, the moderating role of perceived social support from significant other was investigated. While EMS was significantly and negatively associated with caregiver well-being for basic needs $(\beta=-0.24, t(96)=-2.70$, $\mathrm{p}<0.01)$, perceived social support from significant other was significantly and positively associated with caregiver well-being for basic needs $(\beta=0.32, t(96)=3.51$, $\mathrm{p}<0.01 ; \mathrm{F}(2.96)=10.63, \mathrm{p}<0.001)$. The interaction of perceived social support from significant other and EMS was also significant $(\beta=0.26, \mathrm{t}(95)=2.88, \mathrm{p}<0.01$, $\Delta \mathrm{R}^{2}=0.07$; Fchange $\left.(1.95)=8.29, \mathrm{p}<0.01\right)$. In other words, perceived social support from significant other moderated the relation between EMS and caregiver well-being for basic needs (Table 5).

Figure 2 shows the interaction effect of perceived social support from significant other and EMS on the caregiver well-being for basic needs. Using the proposed procedures (77), the simple regression of the caregiver well-being for basic needs on the EMS was computed for high (8.24) and low (-8.24) levels of perceived social support from significant others (i.e., $\mathrm{M}+\mathrm{SD}$ ). The slope of each regression line was then tested to see whether they were statistically significant (76). This analysis revealed that the positive regression of the caregiver well-being for basic needs on the EMS occurs when the perceived social support from significant others is low $(\beta=-0.50, t(95)=-3.82, p<0.001)$ but does not occur when it is high $(\beta=0.01, \mathrm{t}(95)=0.09, \mathrm{p}=0.93)$.
Accordingly, when the perceived social support from the significant other was high, there was no significant difference between the high and low EMS groups in predicting the caregiver well-being for basic needs. In other words, if the caregivers of dementia patients perceived higher levels of social support from significant others, having higher or lower schema scores did not make a difference in terms of caregiver well-being for basic needs. However, when perceived social support from the significant other was low, there was a difference between the high and low EMS groups in predicting caregiver well-being for basic needs. That is, caregivers of dementia patients with higher schema scores had lower well-being (i.e., less fullfilling their basic needs) as compared to caregivers with lower schema scores if they perceived low social support from significant others. Thus, perceived social support from significant others can be a protective factor for caregivers of dementia patients with higher schema scores in terms of caregiver well-being for basic needs.

\section{DISCUSSION}

The present study aimed to investigate the moderating role of perceived social support between the EMS and the caregiver well-being-for basic needs and the caregiver well-being for activities of living. The first hypothesis about the moderating role of perceived social support in the relationship between the EMS and the caregiver well-being for basic needs was supported by the findings. However, the second hypothesis that the perceived social support has a moderating in the relationship between the EMS and the caregiver well-being for activity of living was not supported by the present study. In addition, the moderating role of perceived social support in the relationship between the EMS and the caregiver well-being for basic needs was only supported for perceived social support from significant other. As stated, the moderating variable affects the direction and strength of the relationship between independent and dependent variables as a third variable (78). In other words, the strength of the relationship between the EMS and the caregiver well-being for basic needs was affected by the degree of social support perceived by the caregivers. Accordingly, when perceived social support was high, but not when it was low, a higher schema score was associated with better caregiver well-being. Thus, perceived social support can be considered as a protective factor for caregivers of dementia patients with higher schema scores in terms of caregiver well-being. 
This finding is also in parallel to the stress-buffering hypothesis (60). For those who care for people with dementia, effective social support has been recognized as a stress modifier, which is, in turn, related to better caregiver health and more positive caregiver health outcomes over time (79). Only one source of perceived social support, namely perceived social support from significant other, moderated the EMS -caregiver well-being for basic needs relation. Similar to total perceived social support, when perceived social support from significant other was high, but not when it was low, higher schema scores were associated with better caregiver well-being. That is to say, higher perceived social support from significant other buffered the negative effects of high schema scores, which in turn led to higher well-being in caregivers. The items in the significant others subscale of the Multidimesional Scale of Perceived Social Support (MSPSS) used the date, fiance, relatives, neighbors and doctors as significant others (75). Considering the date and fiance as partners, it is known that partners are the first choice among the sources of support for caregivers (80). As Bowlby (1988) stated, partner support does also provide comfort; it is relaxing (81). The present study indicated that partner support has a protective role. While there are many studies of perceived social support from different sources (63), only a few study have evaluated doctors and neighbors as significant others (82). For example, for the parents of children with autistic spectrum disorder, medical and neighbor support had an impact on the quality of life of parents (82). When considered within the context of dementia, caregivers need advice and information on how to deal with the behavioral problems of the care receiver, the course of the disease, and the scheduling of the care. It was stated that spouses and children caregivers have different needs; spouses need more emotional support and children need more information (83). Given the fact that adult children of dementia patients were evaluated within the scope of this study and that caregivers need more information, it is understood that the support they perceive from doctors is protective for them.

Moreover, another study reported that as dementia progresses, caregivers experience social withdrawal and need more professional help (84). In other words, in the context of advanced dementia, social withdrawal limits the support the caregivers can receive from other sources and requires and demands more support from doctors. Thus, when the needed support from the doctor is perceived by the caregiver, it is plausible that this source of support also has a protective role. As for neighbor support, it can be very important in diseases that affect the daily life of individuals such as dementia (7). For example, individuals diagnosed with dementia may get lost (85), and even in this context, having neighbor support might be very important for caregivers. Therefore, caregivers' needs change as dementia progresses and these changing needs necessitate different types of assistance that can be provided by different sources.

The moderating role of perceived social support on the EMS and caregiver well-being for activities of living relationship was not supported. This finding was surprising because in the previous studies, activities of living were significantly associated with caregiver well-being (72). According to caregiver well-being for activities of living, this finding is surprising and difficult to interpret, because this scale is also a sub-scale of the caregiver well-being. In addition, the items in this scale seem to be related to social support more than the basic needs subscale. For example, the items such as attending social events, allocating time for activities done with family or friends to have a good time, asking for support from family or friends, and getting support from family or friends. In addition, unlike the findings of the present study, a study supporting the moderating role of perceived social support in the association between the caregiver well-being for activities of living and the psychologicalsymptoms was also found in the literatüre (86). However, in one study, caregivers of individuals diagnosed with dementia stated that they did not seek help because they were worried about disturbing their family members (87). For this reason, caregivers may not be able to seek help unless they have to meet their basic, survival needs. While it may seem unnecessary to ask for help to socialize with a friend, they may seek help to eat, sleep, or going to the doctor. In this sense, perceived social support should not be expected to be protective in terms of activities of daily living, but basic needs.

The present study is important in terms of capturing the effect of EMS, and social support on caregiving processes. To the best of our knowledge, the current research is one of the few studies on EMS of dementia caregivers. However, there are also several limitations that should be mentioned at this point. Firstly, the gender distribution of the sample was unequal; the number of male participants was disproportionately low. The reason for this problem was that the participants who brought their parents to the appointments with physicians or Alzheimer Association were mostly the daughters of the patients. Although some patients came to the hospital with their sons, these male caregivers reported their sisters as the primary caregivers. However, considering 
the caregiver literature stating that caregivers are mostly women $(10,11)$, the unequal gender ratio in the present study may not be seen as a limitation. Secondly, it is difficult to find dementia caregivers to fill out the questionnaires, this may be because of their higher responsibility, or higher levels of distress related to caregiving. This is a common problem in caregiver studies (88-91). Therefore, the present study revealed the results of the caregivers who were willing had time to participate in the study. Third, all measures were based on self-reports of the participants. For example, schemas might have been covered by avoidance and overcompensation (38). Individuals might have reported lower levels of schemas than they actually have. Therefore, other data collecting techniques, such as semi-structured interviews can be used for more comprehensive results. Fourth, the small sample size limits the generalizability and statistical power of the results. This sample is heterogeneous in terms of caregivers' demographic characteristics (i.e., gender, age, marital status, educational status). Fifth, the current study is cross-sectional, and it is impossible to plot a cause-effect relationship and observe changes in measurements over a period of time. Finally, the current study did not examine variables related to dementia patients; only the level of the disease was taken into account. However, the characteristics of the patients and the level of the disease affecting the caregivers' lives were not taken into consideration. It should also take into account whether the caregivers seek and/or receive assistance from others and the time spent on caregiving activities.

The present findings have several implications. First of all, caregiving to dementia patients is stressful (2327) and demanding (92). This may increase the requirements and benefits of the intervention programs. In the light of our findings, the inclusion of EMS in the the well-being treatment of dementia caregivers might be important for a better outcome. In addition, the results of this study revealed that perceived social support can be important as a protective factor for caregivers. Therefore, the results of this study provided may not be sufficient to increase well-being in dealing with maladaptive cognitions, but it is also important to help individuals seek and receive higher levels of social support, especially from significant others. Briefly, intervention programs aimed at increasing individuals' perceived social support may be helpful for caregivers' well-being, and this benefit can be more than expected, as many caregivers do not ask for support (93).

Future studies should explore the gender difference and sameness between care receiver and caregiver. The impact of this gender compability/incompability between caregiver and care receiver on well-being can be examined. In addition, in this study, the total EMS score was used. In future studies, the factors of these measures can be handled to see the bigger picture in more details. Moreover, in future studies, to obtain more accurate results and to eliminate the limitations of self-report questionnaires, different data collection techniques such as interviews can be used. In future studies, model testing can be performed on larger samples to identify risk and protective factors for caregiver well-being.

In conclusion, the current study aimed at testing the predictive roles of perceived social support and EMS in the well-being levels of primary caregivers of dementia patients. The moderating role of perceived social support, especially perceived social support from significant other, in the relationship between EMS and the caregiver well-being for basic needs was supported. Thus, perceived social support (from significant others, in particular) can be a protective factor for caregivers of dementia patients with higher schema scores in terms of the caregiver well-being for basic needs. This finding is parallel to the stress-buffering hypothesis (60). The significant finding related to perceived social support from significant other indicated the importance of spousal support in coping with stressful events (81, 94-96). The present study is the first in the literature examining the effects of EMS and perceived social support on caregiving processes. However, the sample represents only the caregivers who are willing to take part in the research and have time to participate in the study. Moreover, the collected data relied on self-report instruments. These factors and the small sample size limited the generalizability of the findings. In terms of the clinical implications, intervention programs related to perceived social support can be developed to increase caregivers' well-being. In future researches, longitudinal and comparative data collected from larger samples and analyzed with model testing can provide a better insight into the well-being of dementia caregivers.

\begin{tabular}{|c|c|c|}
\hline \multicolumn{2}{|c|}{ Contribution Categories } & \multirow{2}{*}{$\begin{array}{l}\text { Author Initials } \\
\text { E.Y., O.B. }\end{array}$} \\
\hline \multirow{3}{*}{ Category 1} & Concept/Design & \\
\hline & Data acquisition & E.Y. \\
\hline & Data analysis/Interpretation & E.Y., O.B. \\
\hline \multirow{2}{*}{ Category 2} & Drafting manuscript & E.Y., O.B. \\
\hline & Critical revision of manuscript & O.B. \\
\hline Category 3 & Final approval and accountability & E.Y., O.B. \\
\hline \multirow{2}{*}{ Other } & Technical or material support & O.B. \\
\hline & Supervision & O.B. \\
\hline
\end{tabular}


Informed Consent: Participants were instructed on the purpose and design of the study, and the informed consents were obtained.

Peer-review: Externally peer-reviewed.

Conflict of Interest: The authors declare that they have no conflict of interest.

Financial Disclosure: The authors declare that they have no financial support.

\section{REFERENCES}

1. Turkish Statistical Institute. Elderly statistics, 2019. https:// data.tuik.gov.tr/Bulten/Index?p=Istatistiklerle-Yaslilar-201933712\#: :text $=$ Ya\%C5\%9Fl\%C4\%B1\%20n\%C3\%BCfus\%20 olarak\%20kabul\%20edilen,9\%2C1'e\%20y\%C3\%BCkseldi. Accessed April 15, 2020.

2. World Health Organization (WHO). Global health and aging. https://www.who.int/ageing/publications/global_health.pdf. Accessed February 20, 2020.

3. World Health Organization (WHO). The epidemiology and impact of dementia. https://www.who.int/mental_health/ neurology/dementia/dementia_thematicbrief epidemiology.pdf. Accessed February 12, 2020

4. Arslantas D, Ozbabalik D, Metintas S, Ozkan S, Kalyoncu C, Ozdemir G, et al. Prevalence of dementia and associated risk factors in Middle Anatolia, Turkey. J Clin Neurosci 2009; 16:1455-1459. [CrossRef]

5. Gurvit H, Emre M, Tinaz S, Bilgic B, Hanagasi H, Sahin H, et al. The prevalence of dementia in an urban Turkish population. Am J Alzheimers Dis Other Demen 2008; 23:67-76. [CrossRef]

6. Keskinoglu P, Yaka E, Ucku R, Yener G, Kurt P. Prevalence and risk factors of dementia among community dwelling elderly people in İzmir, Turkey. Turk Geriatri Derg 2013; 16:135-141.

7. Alzheimer's Association. What İs dementia? https://www.alz. org/alzheimers-dementia/what-is-dementia. Accessed February $15,2020$.

8. Plassman BL, Langa KM, Fisher GG, Heeringa SG, Weir DR, Ofstedal MB, et al. Prevalence of dementia in the United States: the aging, demographics, and memory study. Neuroepidemiology 2007; 29:125-132. [CrossRef]

9. Alzheimer's Association. 2018 Alzheimer's disease facts and figures. https://www.alz.org/media/Documents/ facts-and-figures-2018-r.pdf. Accessed February 13, 2020.

10. Heru AM, Ryan CE. Family functioning in the caregivers of patients with dementia: one-year follow-up. Bull Menninger Clin 2006; 70:222-231. [CrossRef]

11. Heru AM, Ryan CE, Iqbal A. Family functioning in the caregivers of patients with dementia. Int J Geriatr Psychiatry 2004; 19:533537. [CrossRef]

12. Wimo A, Prince M. Alzheimer's disease international: World Alzheimer Report 2010. The global economic Impact of dementia. http://www.alz.co.uk/research/files/ WorldAlzheimerReport2010.pdf. Accessed March 5, 2020.

13. Perren S, Schmid R, Herrmann S, Wettstein A. The impact of attachment on dementia-related problem behavior and spousal caregivers' well-being. Attach Human Dev 2007; 9:163-178. [CrossRef]

14. Pinquart $M$, Sorensen S. Differences between caregivers and non-caregivers in psychological health and physical health: A meta-analysis. Psychol Aging 2003; 18:250-267. [CrossRef]

15. Lawton MP, Moss M, Kleban MH, Glicksman A, Rovine M. A two-factor model of caregiving appraisal and psychological well-being. J Gerontol 1991; 46:P181-P189. [CrossRef]

16. Berg-Weger M, Rubio DM, Tebb SS. The caregiver well-being scale revisited. Health Soc Work 2000; 25:255-263. [CrossRef]

17. Schulz R, Mendelsohn AB, Haley WE, Mahoney D, Allen RS, Zhang S, et al. End-of-life care and the effects of bereavement on family caregivers of persons with dementia. N Eng J Med 2003; 349:1936-1942. [CrossRef]

18. Langa KM, Chernew ME, Kabeto MU, Regula Herzog A, Beth Ofstedal M, Willis RJ, et al. National estimates of the quantity and cost of informal caregiving for the elderly with dementia. J Gen Intern Med 2001; 16:770-778. [CrossRef]

19. Altuntas O, Koc C. Investigation of activity performance of primer caregivers of individuals with dementia. Journal of Occupational Therapy and Rehabilitation 2015; 3:35-44. [Turkish]

20. Gallant MP, Connell CM. Predictors of decreased self-care among spouse caregivers of older adults with dementing illnesses. J Aging Health 1997; 9:373-395. [CrossRef]

21. Simpson C, Carter P. Dementia behavioral and psychiatric symptoms: Effect on caregiver's sleep. J Clin Nurs 2013; 22:30423052. [CrossRef]

22. Wang J, Xiao LD, He G, De Bellis A. Family caregiver challenges in dementia care in a country with undeveloped dementia services. J Adv Nurs 2014; 70:1369-1380. [CrossRef]

23. Andren S, Elmstahl S. Relationships between income, subjective health and caregiver burden in caregivers of people with dementia in group living care: a cross-sectional community-based study. Int J Nurs Stud 2007; 44:435-446.[CrossRef]

24. Bertrand RM, Fredman L, Saczynski J. Are all caregivers created equal? Stress in caregivers to adults with and without dementia. J Aging Health 2006; 18:534-551. [CrossRef]

25. Le'vesque L, Ducharme F, Lachance L. Is there a difference between family caregiving of institutionalized elders with or without dementia? West J Nurs Res 1999; 21:472-497. [CrossRef]

26. Pinquart M, Sorensen S. Associations of stressors and uplifts of caregiving with caregiver burden and depressive mood: A metaanalysis. J Gerontol Psychol Sci 2003; 58B:P112-P128. [CrossRef]

27. Vedhara K, Cox NK, Wilcock GK, Perks P, Hunt M, Anderson $\mathrm{S}$, et al. Chronic stress in elderly carers of dementia patients and antibody response to influenza vaccination. Lancet 1999; 353:627-631. [CrossRef]

28. Vitaliano PP, Zhang J, Scanlan JM. Is caregiving hazardous to one's physical health? A metaanalysis. Psychol Bull 2003; 129:946-972. [CrossRef]

29. Mausbach BT, Chattillion E, Roepke SK, Ziegler MG, Milic M, von Känel R, et al. A longitudinal analysis of the relations among stress, depressive symptoms, leisure satisfaction, and endothelial function in caregivers. Health Psychol 2012; 31:433-440. [CrossRef] 
30. Mausbach BT, Roepke SK, Ziegler MG, Milic M, von Känel R, Dimsdale JE, et al. Association between chronic caregiving stress and impaired endothelial function in the elderly. J Am Coll Cardiol 2010; 55:2599-2606. [CrossRef]

31. Roepke SK, Mausbach BT, Patterson TL, Von Känel R, AncoliIsrael $\mathrm{S}$, Harmell $\mathrm{AL}$, et al. Effects of alzheimer caregiving on allostatic load. J Health Psychol 2011; 16:58-69. [CrossRef]

32. Mills PJ, Adler KA, Dimsdale JE, Perez CJ, Ziegler MG, AncoliIsrael $\mathrm{S}$, et al. Vulnerable caregivers of Alzheimer disease patients have a deficit in $\beta 2$-adrenergic receptor sensitivity and density. Am J Geriatr Psychiatry 2004; 12:281-286. [CrossRef]

33. Mahoney R, Regan C, Katona C, Livingston G. Anxiety and depression in family caregivers of people with Alzheimer's disease - the LASER-AD study. Am J Geriatr Psychiatry 2005; 13:795-801. [CrossRef]

34. Fauth EB, Gibbons A. Which behavioral and psychological symptoms of dementia are the most problematic? Variability by prevalence, intensity, distress ratings, and associations with caregiver depressive symptoms. Int J Geriatr Psychiatry 2014; 29:263-271. [CrossRef]

35. Cassidy J, Shaver PR. Handbook of Attachment: Theory, Research, and Clinical Applications. NY: Guilford Press, 2009.

36. Segal Z. Appraisal of the self-schema: Construct in cognitive models of depression. Psychol Bull 1988; 103:147-162. [CrossRef]

37. Shaver PR, Fraley RC. Attachment, Loss, and Grief: Bowlby's Views and Current Contraversies. In J Cassidy, PR Shaver (editors). Handbook of Attachment: Theory, Research, and Clinical Applications. New York: Guilford Press, 2009, 48-77.

38. Young JE, Klosko JS, Weishaar ME. Schema Therapy: A Practitioner's Guide. New York: The Guilford Press, 2003. [CrossRef]

39. Welburn K, Coristine M, Dagg P, Pontefract A, Jordan S The schema questionnaire-short form: factor analysis and relationship between schemas and symptoms. Cognit Ther Res 2002; 26:519-530. [CrossRef]

40. Calvete E, Orue I, Hankin BL. Transactional relationships among cognitive vulnerabilities, stressors, and depressive symptoms in adolescence. J Abnorm Child Psychol 2013; 41:399-410. [CrossRef]

41. Kim JE, Lee SW, Lee SJ. Relationship between early maladaptive schemas and symptom dimensions in patients with obsessivecompulsive disorder. Psychiatry Res 2014; 215:134-140. [CrossRef]

42. Muris P. Maladaptive schemas in non-clinical adolescents: relations to perceived parental rearing parental rearing behaviours, big five personality factors and psychopathological symptoms. Clin Psychol Psychother 2006; 13:405-413. [CrossRef]

43. Oliveira C, Nobre PJ. Cognitive structures in women with sexual dysfunction: the role of early maladaptive schemas. J Sex Med 2013; 10:1755-1763. [CrossRef]

44. Bortolon C, Capdevielle D, Boulenger JP, Gely-Nargeot MC, Raffard S. Early maladaptive schemas predict positive symptomatology in schizophrenia: A cross-sectional study. Psychiatry Res 2013; 209:361-366. [CrossRef]

45. Saariaho THJ, Saariaho ASI, Karila IA, Joukamaa MI. Early maladaptive schemas in Finnish adult chronic male and female pain patients. Scand J Pain 2010; 1:196-202. [CrossRef]

46. Roper L, Dickson JM, Tinwell C, Booth PG, McGuire J.
Maladaptive cognitive schemas in alcohol dependence: Changes associated with a brief residential abstinence program. Cognit Ther Res 2010; 34: 207-215. [CrossRef]

47. Brotchie J, Meyer C, Copello A, Kidney R, Waller G. Cognitive representations in alcohol and opiate abuse: The role of core beliefs. Br J Clin Psychol 2004; 43:337-342. [CrossRef]

48. Shorey RC, Stuart GL, Anderson S. Early maladaptive schemas among young adult male substance abusers: A comparison with a non- clinical group. J Subst Abuse Treat 2013; 44:522-527.

49. Lawrance KA, Allen JS, Chanen AM. A study of maladaptive schemas and borderline personality disorder in young people. Cognit Ther Res 2011; 35:30-39. [CrossRef]

50. McLean HR, Bailey HN, Lumley MN. The secure base script: Associated with early maladaptive schemas related to attachment. Psychol Psychother 2014; 87:425-446. [CrossRef]

51. Simard V, Moss E, Pascuzzo K. Early maladaptive schemas and child and adult attachment: A 15-year longitudinal study. Psychol Psychother 2011; 84:349-366. [CrossRef]

52. Roelofs J, Onckels L, Muris P. Attachment quality and psychopathological symptoms in clinically referred adolescents: The mediating role of early maladaptive schema. J Child Fam Stud 2013; 22:377-385. [CrossRef]

53. Roelofs J, Lee C, Ruijten T, Lobbestael J. The mediating role of early maladaptive schemas in the relation between quality of attachment relationships and symptoms of depression in adolescents. Behav Cogn Psychother 2011; 39:471-479. [CrossRef]

54. Magai C, Cohen CI. Attachment style and emotion regulation in dementia patients and their relation to caregiver burden. J Gerontol B Psychol Sci Soc Sci 1998; 53B:P147-P154. [CrossRef]

55. Carnelley KB, Pietromonaco PR, Jaffe K. Attachment, caregiving, and relationship functioning in couples: Effects of self and partner. Pers Relatsh 1996; 3:257-278. [CrossRef]

56. Carpenter BD. Attachment bonds between adult daughters and their older mothers: Associations with contemporary caregiving. J Gerontol B Psychol Sci Soc Sci 2001; 56:P257-P266. [CrossRef]

57. Crispi EL, Schiaffino K, Berman WH. The contribution of attachment to burden in adult children of institutionalized parents with dementia. Gerontologist 1997; 37:52-60. [CrossRef]

58. Daire AP. The influence of parental bonding on emotional distress in caregiving sons for a parent with dementia. Gerontologist 2002; 42:766-771. [CrossRef]

59. Cobb S. Social support as a moderator of life stress. Psychosom Med 1976; 38:300-314. [CrossRef]

60. Cohen S, Wills TA. Stress, social support, and the buffering hypothesis. Psychol Bull 1985; 98:310-357. [CrossRef]

61. Mackinnon SP. Perceived social support and academic achievement: Cross-lagged panel and bivariate growth curve analyses. J Youth Adolesc 2012; 41:474-485. [CrossRef]

62. Haber MG, Cohen JL, Lucas T, Baltes BB. The relationship between self-reported received and perceived social support: A meta-analytic review. Am J Community Psychol 2007; 39:133-144.

63. Chiou CJ, Chang HY, Chen IP, Wang HH. Social support and caregiving circumstances as predictors of caregiver burden in Taiwan. Arch Gerontol Geriatr 2009; 48:419-424. [CrossRef] 
64. Thoits PA. Stress, coping and social support processes: Where are we? What next? J Health Soc Behav 1995; Spec No:53-79.

65. Bozo O, Anahar S, Ates G, Etel E. Effects of illness representation, perceived quality of information provided by the healthcare professional, and perceived social support on depressive symptoms of the caregivers of children with leukemia. J Clin Psychol Med Settings 2010; 17:23-30. [CrossRef]

66. Ozpolat AGY, Ayaz T, Konag O, Ozkan A. Attachment style and perceived social support as predictors of biopsychosocial adjustment to cancer. Turk J Med Sci 2014; 44:24-30. [CrossRef]

67. Chappell N, Reid R. Burden and well-being among caregivers: Examining the distinction. Gerontologist 2002; 42:772-780.

68. Bergman-Evans BF. Alzheimer's and related disorders: loneliness, depression, and social support of spousal caregivers. J Gerontol Nurs 1994; 20:6-9. [CrossRef]

69. Brummett BH, Babyak MA, Siegler IC, Vitaliano PP, Ballard EL, Gwyther LP, et al. Associations among perceptions of social support, negative affect, and quality of sleep in caregivers and noncaregivers. Health Psychol 2006; 25:220-225. [CrossRef]

70. Young JE. Schema therapy in applications in borderline and narcissistic personality disorders. Schema Therapy Symposium II, 2006.

71. Soygut G, Karaosmanoglu A, Cakir Z. Assessment of early maladaptive schemas: A psychometric study of the Turkish young schema questionnaire-short form-3. Turk J Psychiatry 2009; 20:75-84. [Turkish]

72. Demirtepe D, Bozo O. Caregiver well-being scale: A study of validity and reliability. Turkish Psychological Articles 2009; 12:28-37. [Turkish]

73. Zimet GD, Dahlem NW, Zimet SG, Farley GK. The multidimensional scale of perceived social support. J Pers Assess 1988; 52:30-41. [CrossRef]

74. Eker D, Arkar H. Perceived social support: psychometric properties of the MSPSS in normal and pathological groups in a developing country. Soc Psychiatry Psychiatr Epidemiol 1995; 30:121-126. [CrossRef]

75. Eker D, Arkar H, Yaldiz H. Factorial structure, validity, and reliability of revised form of the multidimensional scale of perceived social support. Turk J Psychiatry 2001; 12:17-25. [Turkish] [CrossRef]

76. Aiken LS, West SG. Multiple Regression: Testing and Interpreting Interactions. Los Angeles, Sage Publications, 1991.

77. Cohen J, Cohen P, West SG, Aiken LS. Applied multiple Regression / Correlation Analysis for the Behavioral Sciences. New York: Routledge, 2002.

78. Baron RM, Kenny DA. The moderator - mediator variable distinction in social psychological research: Conceptual, strategic, and statistical considerations. J Pers Soc Psychol 1986; 51:1173-1182. [CrossRef]

79. Goode KT, Haley WE, Roth DL, Ford GR. Predicting longitudinal changes in caregiver physical and mental health: A stress process model. Health Psychol 1998; 17:190-198. [CrossRef]

80. Nightingale CL, Curbow BA, Wingard JR, Pereira DB, Carnaby GD. Burden, quality of life, and social support in caregivers of patients undergoing radiotherapy for head and neck cancer: A pilot study. Chronic Illn 2016; 12:236-245. [CrossRef]

81. Bowlby JA. Secure Base: Clinical Applications of Attachment Theory. London: Tavistock/Routledge, 1988.

82. Hsiao YJ. Pathways to mental health-related quality of life for parents of children with autism spectrum disorder: roles of parental stress, children's performance, medical support, and neighbor support. Res Autism Spectr Disord 2016; 23:122-130.

83. Peeters JM, van Beek AP, Meerveld JH, Spreeuwenberg PM, Francke AL. Informal caregivers of persons with dementia, their use of and needs for specific professional support: a survey of the National Dementia Programme. BMC Nurs 2010; 9:9. [CrossRef]

84. Nordtug B, Krokstad S, Sletvold O, Holen A. Differences in social support of caregivers living with partners suffering from COPD or dementia. Int J Older People Nurs 2011; 8:93-103. [CrossRef]

85. Savva GM, Zaccai J, Matthews FE, Davidson JE, McKeith I, Brayne C. Prevalence, correlates and course of behavioural and psychological symptoms of dementia in the population. Br J Psychiatry 2009; 194:212-219. [CrossRef]

86. Demirtepe-Saygili D, Bozo Ö. Perceived social support as a moderator of the relationship between caregiver well-being indicators and psychological symptoms. J Health Psychol 2011; 16:1091-1100. [CrossRef]

87. Au A, Shardlow SM, Teng YUE, Tsien T, Chan C. Coping strategies and social support-seeking behaviour among Chinese caring for older people with dementia. Ageing Soc 2013; 33:1422-1441. [CrossRef]

88. Barrera M, D'agostino NM, Gibson J, Gilbert T, Weksberg R, Malkin D. Predictors and mediators of psychological adjustment in mothers of children newly diagnosed with cancer. Psychooncology 2004; 13:630-641. [CrossRef]

89. Coope B, Ballard C, Saad K, Patel A, Bentham P, Bannister C, et al. The prevalence of depression in the carers of dementia sufferers. Int J Geriatr Psychiatry 1995; 10:237-242. [CrossRef]

90. De Vugt ME, Stevens F, Aalten P, Lousberg R, Jaspers N, Winkens I, et al. Behavioural disturbances in dementia patients and quality of the marital relationship. Int J Geriatr Psychiatry 2003; 18:149-154. [CrossRef]

91. Kazak AE, Barakat LP, Meeske K, Christakis D, Meadows AT, Casey $\mathrm{R}$, et al. Posttraumatic stress, family functioning, and social support in survivors of childhood leukemia and their mothers and fathers. J Consult Clin Psychol 1997; 65:120-129.

92. Rosa E, Lussignoli G, Sabbatini F, Chiappa A, Di Cesare S, Lamanna L, et al. Needs of caregivers of the patients with dementia. Arch Gerontol Geriatr 2010; 51:54-58. [CrossRef]

93. Burton AM, Haley WE, Small BJ. Bereavement after caregiving or unexpected death: effects on elderly spouses. Aging Ment Health 2006; 10:319-326. [CrossRef]

94. Giese-Davis J, Hermanson K, Koopman C, Weibel D, Spiegel D. Quality of couples' relationship and adjustment to metastatic breast cancer. J Fam Psychol 2000; 14:251-266. [CrossRef]

95. Jackson PB. Specifying the buffering hypothesis: Support, strain, and depression. Soc Psychol Q 1992; 55:363-378. [CrossRef]

96. Manne S, Ostroff J, Winkel G, Goldstein L, Fox K, Grana G. Posttraumatic growth after breast cancer: patient, partner, and couple perspectives. Psychosom Med 2004; 66:442-454. [CrossRef] 